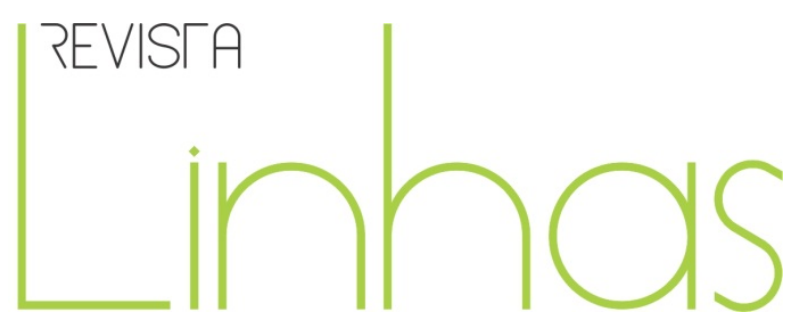

\title{
Questão racial, ações afirmativas e currículo: uma discussão em torno das diretrizes para a educação das relações étnico-raciais
}

\begin{abstract}
Resumo
Este artigo tem por propósito problematizar algumas implicações educacionais das atuais políticas públicas de ação afirmativa, desenvolvidas pelo Governo Federal desde meados da década de 1990. Interessa abordar as especificidades das ações afirmativas que intervêm sobre o recorte étnico-racial da população brasileira, tomando por objeto central de análise a dimensão curricular de suas implicações educacionais. A institucionalização dessas políticas públicas é fator de grande relevância para o processo histórico que conduziu ao fenômeno contemporâneo, aqui definido como a politização da questão racial brasileira. Partindo das Diretrizes Curriculares Nacionais para a Educação das Relações Étnico-Raciais, busco compreender certas interlocuções entre suas proposições e o caráter eminentemente político que a raça e as relações raciais assumiram em nosso País durante as últimas décadas.
\end{abstract}

Gustavo da Silva Kern

Doutorando em Educação pela

Universidade Federal do Rio Grande do Sul - UFRGS xkern@hotmail.com

Palavras-chave: Questão racial; Ações afirmativas; Currículo.

\section{Para citar este artigo:}

KERN, Gustavo da Silva. Questão racial, ações afirmativas e currículo: uma discussão em torno das diretrizes para a educação das relações étnico-raciais. Revista Linhas, Florianópolis, v. 15, n. 28, p. 324-344, jan./jun. 2014 .

DOI: $10.5965 / 1984723815282014324$

http://dx.doi.org/10.5965/1984723815282014324 


\title{
Racial question, affirmative action and curriculum: a discussion around the guidelines for the education of ethnic and racial relations
}

\begin{abstract}
This article has the purpose to problematize some educational implications of current public policies of affirmative action, developed by the Federal Government since the mid-1990s. Address the specific interests of affirmative action that intervenes on the ethnic-racial population, taking as a central object of analysis the size of your curricular educational implications. The institutionalization of these policies is highly relevant to the historical process that led to the contemporary phenomenon defined here as the politicization of race in Brazil. Leaving the National Curriculum Guidelines for the Education of EthnicRacial Relations, I wish to understand certain dialogues between their proposals and eminently political race and race relations in our country have taken during the last decades.
\end{abstract}

Keywords: Racial question; Affirmative action; Curriculum. 
Tem-se feito um esforço para que a questão da "raça" seja reconhecida com seriedade na teoria política em geral, no pensamento jornalístico e acadêmico. Esse silêncio tem sido rompido à medida que esses termos se impõem sobre sua consciência política. Sua crescente visibilidade constitui, inevitavelmente, um processo difícil e pesado. Além do mais, encontramos agora "raça" entre parênteses, "raça" sob rasura, "raça" em uma nova configuração com etnicidade. Esse deslocamento epistêmico constitui um dos efeitos mais transruptivos do multicultural.

Stuart Hall ${ }^{1}$

No interessante ensaio intitulado A Questão Multicultural, o teórico da cultura Stuart Hall assinala um elemento característico das tensões sociais em diferentes sociedades contemporâneas: a centralidade que a dimensão política da noção de raça assumiu nas últimas décadas. De acordo com o argumento apresentado no transcorrer do presente artigo, as atuais políticas públicas de ação afirmativa ${ }^{2}$ - que objetivam atuar especificamente sobre o recorte racial da população - emergem e se constituem sob o signo de um efetivo processo de politização da questão racial no Brasil. Este fenômeno, que teve lugar no transcorrer das últimas décadas, criou as condições para a emergência de políticas afirmativas, traço mais marcante desta politização da raça e das relações raciais.

Todavia, mesmo que o fenômeno discursivo assinalado por Hall constitua um lugar comum nos debates políticos travados em diversos Estados-nação, tal como o Brasil, deve-se ter em conta que a temática da raça e, por conseguinte, das relações raciais, assume contornos particulares na dinâmica histórica de cada formação social. Como afirmou a historiadora Nancy Stepan (2005, p. 19) "as distinções raciais não são perpétuas, mas foram constantemente renegociadas e experimentadas de diversas formas nos distintos períodos históricos". No Brasil, a institucionalização das políticas

\footnotetext{
${ }^{1}$ A Questão Multicultural.

${ }^{2}$ Utilizarei, por vezes, a forma elipsada políticas afirmativas para designar as políticas de ação afirmativa ou ações afirmativas.
} 
afirmativas aconteceu atrelada a um deslocamento nos discursos sobre a questão racial e teve lugar a partir da década de 1990, principalmente através de medidas do governo federal. Tais políticas públicas têm suscitado um instigante debate político que se dá em diversos âmbitos da sociedade: movimentos sociais, academia, partidos políticos, assim como em diferentes instâncias do Executivo, do Legislativo e do Judiciário.

Partindo de uma perspectiva genealógica de análise dos discursos produzidos nos termos de Michel Foucault (2009) - em torno das políticas afirmativas, o interesse deste texto reside justamente em abordar suas implicações curriculares, uma vez que a Educação se tem constituído como campo de intervenção por excelência desse tipo de política pública. Para tanto, debruço-me sobre o texto das Diretrizes Curriculares Nacionais para a Educação das Relações Étnico-Raciais, procurando compreender suas relações com a politização da questão racial brasileira, fenômeno que parece possuir não apenas uma dimensão educacional efetiva, mas também uma dimensão curricular relevante, produto do que Stuart Hall (2009, p. 66) definiu como um dos efeitos mais "transruptivos do multicultural": a afirmação da dimensão política da raça e das relações raciais.

\section{Genealogia e o estudo da questão racial no Brasil}

A reflexão aqui empreendida problematiza, primeiramente, o modo como a proliferação de discursos sobre raça e relações raciais, desde pelo menos meados da década de 1990, vem sendo cada vez mais canalizada pelas tensões em torno das políticas afirmativas, para, então, problematizar suas implicações educacionais e curriculares. No interior desta proliferação discursiva, surgem compreensões diversas sobre o caráter das relações raciais, o que permite que as atuais políticas afirmativas possam ser pensadas como um ponto estratégico no qual as tensões em torno das relações raciais se afirmam. Para analisar as condições de emergência histórica de tais políticas, parece-me adequado ensaiar uma abordagem pouco usual, tomando essa trama de discursos a partir de uma perspectiva genealógica de análise da história. 
Nos termos em que foi inscrita na ontologia do presente de Foucault (2009), a genealogia corresponde a um tipo de teorização da história que, assumidamente, parte de um problema do presente. Tal como aparecera na Genealogia da Moral, de Friedrich Nietzsche, seu objetivo é "descrever uma gênese no tempo" (VEIGA-NETO, 2003, p. 56), questionando a ascendência e as condições de emergência histórica dos fenômenos a serem analisados. Deslocada por Foucault, a genealogia agregaria, como método de exploração das fontes de pesquisa, a análise dos discursos, investigando sua constituição e circulação através de relações entre saber e poder. Como afirmou Foucault (2009, p. 30) em Vigiar e punir, "não há relações de poder sem constituição correlata de um campo de saber, nem saber que não suponha e não constitua ao mesmo tempo relações de poder”. A genealogia, portanto, não é uma história no sentido comum do termo, pois questiona os processos históricos na medida em que dizem respeito à gênese de um problema do presente. Roberto Machado (2009, p. 167) define a genealogia teorizada por Foucault como "uma análise histórica das condições políticas de possibilidades dos discursos".

Essas reflexões e tensões políticas produziram uma trama de discursos dispersos e descontínuos, que mantêm as relações raciais como objeto de uma singular regularidade discursiva no âmbito dos saberes e dos poderes - tome-se como exemplo o controverso debate político em torno da institucionalização das políticas afirmativas de reserva de vagas no ensino superior para estudantes autodeclarados negros e indígenas.

Para problematizar a emergência das políticas afirmativas e suas relevantes implicações para o campo da Educação, bem como para o currículo, entendo que certa atenção sobre a trajetória histórica da questão racial no pensamento brasileiro se impõe como necessidade. Ter em conta certas regularidades e descontinuidades na história dos discursos sobre as relações raciais produzidos no Brasil permite descrever alguns traços genealógicos de ancoragem da proliferação de discursos em torno das políticas afirmativas. Não havendo espaço para uma exploração exaustiva desses discursos, mencionarei, de modo um tanto esquemático, alguns textos acadêmicos, jornalísticos e estatais representativos das interações que a temática da questão racial mantém com as relações saber-poder no Brasil contemporâneo, o que explica sua íntima relação com o debate sobre a emergência das políticas afirmativas. 


\section{A emergência das políticas afirmativas no Brasil}

Grosso modo, as políticas afirmativas de que me ocupo no presente artigo oficializam, do ponto de vista do Estado, determinadas medidas de combate ao fenômeno social do racismo, manifesto nas diversas formas de discriminação. Como afirma Arabela Campos Oliven (2009, p. 66) podem-se tomar como "um conjunto de políticas públicas para proteger grupos que, em uma determinada sociedade, são ou tenham sido discriminados". Legitimadas politicamente através do que Robert Castel (2008), definiu como discriminação positiva a efetivação das políticas afirmativas "visa remover barreiras, formais e informais, que impeçam o acesso de certos grupos ao mercado de trabalho, universidades e posições de poder" (OLIVEN, 2009, p. 66).

Todavia, antes de definir com exatidão, em aspectos essenciais, o que são as políticas de ação afirmativa, é interessante, por ora, problematizar o processo de emergência desse tipo de política pública em nosso país. Ao avançar sobre essa problemática, dedico a segunda parte do texto à discussão em torno da dimensão educacional das políticas afirmativas, debruçando-me especialmente sobre suas implicações curriculares da Lei 10.639/03 e da Lei 11.645/09 (que determinam a obrigatoriedade do ensino de história e cultura afro-brasileira, africana e indígena no ensino básico).

Desse modo, busco abordar o processo de emergência das políticas afirmativas no Brasil pelo modo como têm sido formuladas, propostas e institucionalizadas pelo Estado. Detenho-me, principalmente, sobre os documentos oficiais do governo federal, em especial sobre os que embasam a Política Nacional de Promoção da Igualdade Racial e sobre alguns artigos acadêmicos e jornalísticos que discutem a institucionalização das atuais políticas afirmativas no Brasil - fontes que, na falta de uma expressão mais adequada, chamo de reflexões críticas. Na esteira do que observaram Alfredo Veiga-Neto e Maura Corcini Lopes (2007, p. 6), ao afirmar que "toda a discursividade das e em torno das políticas públicas pode ser compreendida como estratégica para o governamento das populações, penso que o referido conjunto de fontes de pesquisa permite abordar a 
dinâmica das diferentes racionalidades articuladas ao processo de emergência das políticas afirmativas, bem como as implicações educacionais e curriculares dessas políticas públicas."

Enquanto na primeira metade do século $X X$, a raça e as relações raciais foram abordadas, prioritariamente, pelo prisma da ciência, decorrendo disso uma série implicações políticas, como a política oficial de branqueamento, que tinha como condição de existência justamente o melhoramento racial projetado pelo pensamento eugênico. Parece-me que, no transcorrer da segunda metade do século $\mathrm{XX}$, a questão racial brasileira passou a ser encarada como um problema primordialmente político. O debate em torno da metáfora da democracia racial abriu caminho para uma abordagem antes política que científica, tanto da noção de raça, como da própria questão racial.

Desse modo, um primeiro elemento de especificidade, do ponto de vista das relações de poder e da análise genealógica dos discursos, é o seguinte: a emergência das políticas afirmativas esta articulada a certa dimensão política da questão racial. Tomadas como práticas, as ações afirmativas estão colocadas no meio da dinâmica de relações de poder que se enraízam no nexo social. Tendo em vista a trajetória histórica dos debates em torno da raça e das relações raciais na sociedade brasileira, políticas públicas como as ações afirmativas constituem-se como objeto de intensas disputas políticas. Disputas que se afirmam, de um modo especial, na centralidade que o campo da Educação assume junto à institucionalização das ações afirmativas.

A análise da proliferação de discursos em torno das políticas afirmativas define e permite delimitar a participação oficial do governo federal brasileiro na "III Conferência Mundial das Nações Unidas de Combate ao Racismo, Discriminação Racial, Xenofobia e Intolerância Correlata", realizada em 2001, na cidade de Durban, África do Sul, como momento crucial para o processo institucionalização das políticas afirmativas em nosso país. Como signatário da Declaração de Durban, o Estado brasileiro assumiu o compromisso de estabelecer:

[...] com base em informações estatísticas, programas nacionais, inclusive programas de ações afirmativas ou medidas de ação positivas, para promoverem o acesso de grupos de indivíduos que são ou podem 
vir a ser vítimas de discriminação racial nos serviços sociais básicos, incluindo, educação fundamental, atenção primária à saúde e moradia adequada. (ORGANIZAÇÕES, 2001, p. 55-56)

Para Ali Kamel, autor do controverso Não somos racistas, a partir do momento em que o governo federal ratificou o "Programa de Ação" da Declaração de Durban "todos nós acordamos num país diferente, comprometido oficialmente com a adoção de políticas de preferência racial” (KAMEL, 2006, p. 35), dando as costas ao ideal de nação fundado "nas virtudes de nossa miscigenação, da convivência harmoniosa entre todas as cores" (KAMEL, 2006, p. 40). Já os antropólogos Yvonne Maggie e Peter Fry fazem a seguinte consideração:

[...] entre a promulgação da Constituição brasileira de 1988 e a III Conferência Mundial das Nações Unidas de Combate ao Racismo, Discriminação Racial, Xenofobia e Intolerância Correlata, que teve lugar em Durban, na África do Sul, em 2001, a postura do governo do Brasil perante a questão racial mudou radicalmente. [...] As medidas [governamentais] pós-Durban, ao proporem ações afirmativas em prol da "população negra", rompem não só com o a-racismo e o anti-racismo tradicionais, mas também com a forte ideologia que define o Brasil como país da mistura, ou, como preferia Gilberto Freyre, do hibridismo. (MAGGIE; FRY, 2004, p. 67)

Os trabalhos referidos atribuem à Conferência de Durban uma importância central para os rumos da institucionalização das ações afirmativas como política de Estado. Entendem os autores que a posição assumida pelo Estado brasileiro em Durban, onde o Brasil assumiu o compromisso de promover políticas afirmativas de recorte racial, foi o principal marco de uma relevante inflexão na postura política oficial frente à questão racial; além disso, assinalam uma articulação entre essa inflexão estatal e uma ruptura oficial com o entendimento segundo o qual a brasilidade é definida pela miscigenação cultural entre as três matrizes étnico-raciais que concorreram para a formação do povo brasileiro. Compreensão da identidade nacional na qual se assentou a histórica utilização política da metáfora da democracia racial.

Como afirmam Maggie e Fry, é principalmente entre o ano de 1988 e o ano de 2001 que se deve procurar entender o que se define como uma mudança radical na postura do 
Estado frente à questão racial. Na Carta Magna de 1988, o Brasil foi definido como uma República federativa e presidencialista de caráter democrático-liberal, nos moldes ocidentais, afirmando princípios básicos de um Estado liberal, como a igualdade de todos perante a lei e a garantia de todos à participação e ao acesso à cultura nacional e conferindo, neste sentido, homogeneidade cultural para a comunidade imaginada que é a nação. No tocante às relações raciais, a Constituição federal condenou o preconceito racial, repudiando o racismo e tornando sua prática crime inafiançável e imprescritível.

No início de seu primeiro mandato como presidente da República, Fernando Henrique Cardoso se notabilizou pelo fato de ter reconhecido, oficialmente, a existência do racismo no Brasil. Ainda em 1995, ano da Marcha Zumbi contra o Racismo, pela Cidadania e a Vida, realizada em Brasília, o governo federal criou, por decreto presidencial, o chamado Grupo de Trabalho Interministerial para a Valorização da População Negra, competindo a ele "elaborar, propor e promover políticas governamentais antidiscriminatórias e de consolidação da cidadania da população negra" (BRASIL, 1996). No Plano Nacional de Direitos Humanos I (PNDH I), lançado em 1996, a promoção de políticas específicas para a população negra surge novamente em destaque. O documento propõe o estabelecimento de vínculos institucionais cada vez mais estreitos entre os movimentos negros e o Estado. Propondo, inclusive, de modo inédito do ponto de vista do governo federal, o desenvolvimento de políticas que instituem direitos específicos para a população negra, com base no critério da discriminação positiva e desenvolvidas na forma de ações afirmativas.

Segundo as reflexões críticas, a inflexão na postura do Estado frente à questão racial, também está articulada ao que Maggie e Fry (2004) definem como uma ruptura de determinada tradição republicana do Brasil. Para esses antropólogos, ao propor a institucionalização de direitos específicos para determinados grupos raciais e admitindo oficialmente uma constituição racial própria à população brasileira, o governo federal rompeu com aquilo que se adjetiva como a forte ideologia que define a mistura e o hibridismo como elementos essenciais da brasilidade, bem como com o valioso ideal da democracia racial. 
Desse modo, a ruptura com a concepção segundo a qual o Brasil figura como um modelo de democracia racial - da qual largamente se serviu o discurso oficial durante o século XX, tanto no período democrático (que se estendeu entre 1945 e 1964), como na ditadura civil-militar (que lhe sucedeu até 1985), surge como fator relevante para a constituição da racionalidade estatal, que dá lugar à emergência das políticas afirmativas. Em Durban, teria a representação brasileira posto em xeque a histórica prática de utilização política da metáfora da democracia racial pelo Estado.

$\mathrm{Na}$ medida em que o governo federal reconheceu, em fórum internacional de grande importância, o vínculo entre as práticas de discriminação racial e as enormes desigualdades socioeconômicas observadas na população brasileira, também admitiu a necessidade de desenvolver políticas afirmativas. Este corte, do ponto de vista dos discursos estatais, surge como movimento de alinhamento a certas proposições políticas que constituíam a pauta das disputas dos movimentos negros desde a década de 1980, tais como a negação da ideia do Brasil como democracia racial e o reconhecimento, numa perspectiva positiva, das especificidades dos grupos sociais então considerados como racialmente discriminados.

No mesmo ano da Conferência de Durban, o governo federal ainda instituiu o Conselho Nacional de Combate à Discriminação e o Plano Nacional de Ações Afirmativas. Ainda no final do segundo mandato de Cardoso, foi lançado o Plano Nacional de Direitos Humanos II (PNDH II). No conjunto de medidas apresentadas pelo PNDH II, o horizonte da ação estatal sobre a questão racial é ampliado, propondo: o reconhecimento das consequências históricas da escravidão; a promoção de políticas públicas de caráter compensatório, desenvolvidas na forma de ações afirmativas e baseadas no critério da discriminação positiva. Políticas que visam a proporcionar a igualdade de oportunidades, principalmente pela "ampliação do acesso dos afrodescendentes às universidades públicas, aos cursos profissionalizantes, às áreas de tecnologia de ponta, aos cargos e empregos públicos" (BRASIL, 2002, p. 16).

A instituição desse conjunto de medidas ficou a cargo da Secretaria Especial de Políticas de Promoção da Igualdade Racial (Seppir), criada pelo governo federal em 2003. No início do primeiro ano de mandato de Luis Inácio Lula da Silva, foi criado, com status 
ministerial no âmbito do governo federal, o órgão "responsável pela formulação, coordenação e articulação de políticas e diretrizes para a promoção da igualdade racial e proteção dos direitos dos grupos raciais e étnicos discriminados, com ênfase na população negra" (BRASIL, 2009, p. 24). A atuação da Seppir é bastante representativa da forma como a racionalidade estatal passou a refletir as relações raciais ainda em meados da década de 1990, e sobre elas intervir, articulando o desenvolvimento da atual Política Nacional de Promoção da Igualdade Racial, que tem por objetivo sistematizar ações no sentido d reduzir as "desigualdades raciais no Brasil, com ênfase na população negra" (BRASIL, 2003).

A Política Nacional de Promoção da Igualdade Racial está fundamentada, principalmente, pelo Plano Nacional de Desenvolvimento da Igualdade Racial (Planapir), lançado pela Seppir em 2009, e pelo Estatuto da Igualdade Racial, aprovado pelo Congresso Nacional no ano de 2010. Ambos os documentos propuseram uma série de intervenções estatais na educação básica e na educação escolar, intervindo do âmbito macroscópico das políticas educacionais até o âmbito microscópico da sala de aula, tanto nas escolas quanto nas universidades. Todavia, e isto me parece um elemento que não deve ser menosprezado, as Diretrizes Curriculares Nacionais para a Educação das Relações Étnico-Raciais foram propostas pelo governo federal em 2004, precedendo os sendo anteriores aos dois documentos já referidos. Como materialidade discursiva com espaço para a interlocução entre as políticas afirmativas e o campo da Educação, essas diretrizes curriculares merecerão uma atenção maior na seção que se segue.

\section{As implicações educacionais e curriculares das políticas afirmativas}

As políticas afirmativas intervêm junto à população brasileira a partir de sua composição racial, tomando a noção de raça em sua ênfase política, buscando exercer a condução das relações raciais ao atuar sobre um fenômeno de massa: as desigualdades educacionais relativas aos efeitos das práticas de discriminação racial. Através de medidas de caráter reparatório, as políticas afirmativas vislumbram reduzir desigualdades 
socioeconômicas, bem como as desigualdades educacionais observadas entre a população nacional.

Nos últimos anos, o debate sobre a efetividade desse tipo de política pública foi pautado por temas como a controversa tramitação do Estatuto da lgualdade Racial no legislativo federal e a decisão do Superior Tribunal Federal (STF) acerca da constitucionalidade da política de reserva de vagas para estudantes autodeclarados negros e indígenas - adotada compulsoriamente no ensino superior em nível nacional durante os últimos anos. Sintomático da centralidade do campo da Educação junto ao processo de emergência das políticas afirmativas é o fato de que a Política Nacional de Promoção da Igualdade Racial — desenvolvida pelo governo federal desde 2003 - teve como uma de suas primeiras medidas a institucionalização de uma série de modificações curriculares na educação básica e na educação superior.

A Lei 10.639/03, que posteriormente foi modificada pela Lei 11.645/09, instituiu a obrigatoriedade do ensino de história e cultura africana, afro-brasileira e indígena em todos os níveis, suscitou a proposição das referidas Diretrizes Curriculares Nacionais para a Educação das Relações Étnico-Raciais. As práticas desenvolvidas em instituições educativas, locus por excelência da constituição das subjetividades, são fundamentais para o engendramento de determinadas formas de condução da população, materializando certas relações bastante explícitas entre saber e poder. Desse modo, para subjetivar a população no sentido da promoção da igualdade racial — objetivo maior da Política Nacional de Promoção da Igualdade Racial —, o currículo, ou seja, aquilo que Alfredo Veiga-Neto definiu como a "programação pedagógica do que é ensinado aos alunos" (VEIGA-NETO, 2010, p. 3), é algo de enorme relevância.

O desenvolvimento da aprendizagem em instituições educacionais acontece em torno, ou a partir, de uma programação curricular das disciplinas e conteúdos previamente estabelecidos pelas diretrizes curriculares. Todavia, como entende VeigaNeto, o currículo, além de sua função interna aos processos educacionais, é também artefato cultural, justamente na medida em que é produto das relações entre as instituições educacionais, os chamados estabelecimentos de ensino, e a sociedade de que fazem parte: 
[...] o currículo está sempre envolvido quando pensamos em intervir na organização disciplinar, seja no que concerne às práticas comportamentais nas salas de aula, seja no que concerne aos conhecimentos a serem ensinados e aprendidos (em termos da sua fragmentação, aproximação e fusão, bem como dos tradicionais o que, como e quando ensinar). Mas ele também está envolvido na composição dos espaços escolares, no que concerne às suas delimitações (em termos de presencialidade e virtualização) e composição (em termos de quem deve ser incluído com quem e quem deve ser separado de quem). E, na medida em que o currículo é, também, um artefato cultural, acabam ressoando dentro da escola todas as transformações que hoje estão a acontecer. (VEIGA-NETO, 2010, p. 4)

Objeto das relações de poder, bem como do jogo entre diferentes tensões políticas e sociais, os saberes e conhecimentos que compõem o currículo são produzidos por especialistas, que, a serviço do Estado, propõem os programas curriculares. A racionalidade estatal, manifesta em documentos oficiais, produzidos por experts, define quais são os conhecimentos válidos e necessários aos estudantes. As diretrizes curriculares voltadas às relações étnico-raciais pretendem orientar a promoção de práticas pedagógicas voltadas a uma reparação histórica, que deverá ser efetivada através de determinados saberes escolares a serem incluídos no currículo, ou seja, nas diretrizes curriculares nacionais. O currículo escolar é aqui entendido, neste sentido, como um meio de acesso do Estado à população.

A enorme contribuição política do campo das Ciências Humanas e, em especial, do campo da Educação para a construção do nacional - em diversos Estados-nação, incluindo o Brasil — já é amplamente conhecida pela produção acadêmica da área. O currículo escolar e universitário se constituiu historicamente como objeto das tensões em torno da definição do caráter nacional, que deveria ser construído através das práticas desenvolvidas em instituições educacionais, principalmente no âmbito do ensino escolar e universitário. As políticas afirmativas, ao institucionalizarem determinadas modificações curriculares, acabaram por se inserir nesta problemática da construção do nacional.

Um elemento de diferenciação dessas políticas afirmativas, frente às demais políticas inclusivas atualmente desenvolvidas pelo governo federal, é a especificidade de serem políticas públicas imbuídas de um caráter racialmente reparatório. Ao contrário da política de branqueamento do início do século XX, levada a cabo pelo Estado durante a 
Primeira República (1889-1930), essa reparação não busca corrigir — através do melhoramento racial - as características físicas e psíquicas de um determinado grupo racial definido biologicamente, mas corrigir os efeitos sociais da discriminação negativa sofrida por determinados grupo étnico-raciais, partindo, desse modo, da compreensão da raça e das relações em sua dimensão social e política, diferente da compreensão biológico-racial que determinou o constructo do ideal do branqueamento.

As políticas afirmativas que atuam sobre a Educação, instituídas através da atual Política Nacional de Promoção da Igualdade Racial, não buscam apenas empreender uma reparação socioeconômica, mas incluir os grupos sociais discriminados, tendo em vista a realidade das drásticas desigualdades étnico-raciais entre a população brasileira. Como afirmam as "Disposições Preliminares" do Estatuto da Igualdade Racial, os programas desenvolvidos na forma de ações afirmativas deverão resultar em "políticas públicas destinadas a reparar as distorções e desigualdades sociais e demais práticas discriminatórias adotadas, nas esferas pública e privada, durante o processo de formação social do País" (BRASIL, 2011, p. 14-15).

Trata-se, também, de utilizar as políticas afirmativas que institucionalizam modificações na educação básica e na educação superior para promover uma reparação histórica. Tal reparação deverá se dar ao nível da compreensão da própria História do Brasil, entendida aqui não apenas como área do conhecimento histórico, mas também como elemento que embasa a constituição de nossas diretrizes curriculares em um âmbito mais geral, uma vez que são nacionalmente unificadas, embora relativamente flexíveis do ponto de vista de sua implementação nas diferentes redes de ensino.

As proposições encontradas nas Diretrizes Curriculares Nacionais para a Educação das Relações Étnico-Raciais, formuladas pelo Ministério da Educação (MEC), juntamente com Secretaria Especial de Promoção da Igualdade Racial, reafirmam o caráter historicamente reparador das políticas afirmativas que intervêm na educação básica. Este importante documento se inicia por um breve panorama da história brasileira, no que diz respeito à questão racial e à educação: 
O Brasil, Colônia, Império e República teve, historicamente, no aspecto legal, uma postura ativa e permissiva diante da discriminação e do racismo que atinge a população afro-descendente brasileira até hoje. $\mathrm{O}$ Decreto $\mathrm{n}^{\circ}$ 1.331, de 17 de fevereiro de 1854, estabelecia que nas escolas públicas do país não seriam admitidos escravos, e a previsão de instrução para adultos negros dependia da disponibilidade de professores. 0 Decreto $\mathrm{n}^{\circ} 7.031-\mathrm{A}$, de 6 de setembro de 1878, estabelecia que os negros só podiam estudar no período noturno e diversas estratégias foram montadas no sentido de impedir o acesso pleno dessa população aos bancos escolares. (BRASIL, 2004, p. 7)

A identidade nacional forjada no âmbito do discurso racialista, que permeou o trabalho de importantes precursores das Ciências Sociais em nosso país como Sílvio Romero, Euclides da Cunha, Nina Rodrigues e Oliveira Viana, negava em grande medida a contribuição de largas camadas da população na formação do Brasil, justificando as diferentes formas de exclusão social das populações negra, índia e mestiça consideradas racialmente inferiores -, que funcionaram junto ao processo de modernização nacional entre as últimas décadas do XIX e as primeiras décadas do século XX. O documento, neste sentido, reitera o argumento político em torno da necessidade de medidas estatais orientadas a corrigir, através de medidas reparatórias, a histórica desigualdade racial:

A demanda por reparações visa a que o Estado e a sociedade tomem medidas para ressarcir os descendentes de africanos negros, dos danos psicológicos, materiais, sociais, políticos e educacionais sofridos sob o regime escravista, bem como em virtude das políticas explícitas ou tácitas de branqueamento da população, de manutenção de privilégios exclusivos para grupos com poder de governar e de influir na formulação de políticas, no pós-abolição. Visa também a que tais medidas se concretizem em iniciativas de combate ao racismo e a toda sorte de discriminações. (BRASIL, 2004, p. 12)

Segundo as Diretrizes Curriculares Nacionais para a Educação das Relações ÉtnicoRaciais, as práticas pedagógicas desenvolvidas nos estabelecimentos de ensino que, de alguma forma, estão ligados ao Estado, assumem uma relevante responsabilidade na efetivação dessa reparação histórica - reparando processos de exclusão produzidos pelo próprio desenvolvimento desigual da escolarização no País, de acordo com o panorama histórico proposto pelo documento. O sucesso das políticas públicas reparatórias dependeria de uma série de condições favoráveis à ação das políticas 
afirmativas. Entre essas, destaca-se a necessidade imprescindível de uma "reeducação das relações entre negros e brancos" (BRASIL, 2004, p. 13). Algo que deve ter lugar, fundamentalmente, a partir de práticas desenvolvidas em instituições educacionais responsáveis pelo funcionamento de mecanismos pedagógicos que viabilizem a “articulação entre processos educativos escolares, políticas públicas, movimentos sociais, visto que as mudanças éticas, culturais, pedagógicas e políticas nas relações étnico-raciais não se limitam à escola" (BRASIL, 2004, p. 13).

Desse modo, muito embora as políticas afirmativas programem intervenções em diversas áreas, o campo da Educação e o currículo assumem centralidade. A política afirmativa, proposta nas referidas diretrizes, é abertamente apresentada como uma política curricular que:

[...] procura oferecer uma resposta, entre outras, na área da educação, à demanda da população afrodescendente, no sentido de políticas de ações afirmativas, isto é, de políticas de reparações, de reconhecimento e valorização de sua história, cultura, identidade. Trata, ele, de política curricular, fundada em dimensões históricas, sociais, antropológicas oriundas da realidade brasileira, e busca combater o racismo e as discriminações que atingem particularmente os negros. Nesta perspectiva, propõe a divulgação e produção de conhecimentos, a formação de atitudes, posturas e valores que eduquem cidadãos orgulhosos de seu pertencimento étnico-racial - descendentes de africanos, povos indígenas, descendentes de europeus, de asiáticos para interagirem na construção de uma nação democrática, em que todos, igualmente, tenham seus direitos garantidos e sua identidade valorizada (BRASIL, 2004, p. 10).

Tal política incorpora os postulados dos trabalhos do sociólogo Florestan Fernandes (2007), assim como as reivindicações políticas históricas dos movimentos negros, com destaque para o Movimento Negro Unificado. As modificações curriculares operadas neste sentido estão intimamente relacionadas ao fenômeno da politização das relações raciais, ao qual já fiz referência. Trata-se de um fenômeno que parece determinar, entre outras, a proposição das seguintes diretrizes para o ensino de História e Cultura Afro-brasileira e Africana:

A obrigatoriedade de inclusão de História e Cultura Afro-Brasileira e Africana nos currículos da Educação Básica trata-se de decisão política, 
com fortes repercussões pedagógicas, inclusive na formação de professores. Com esta medida, reconhecesse que, além de garantir vagas para negros nos bancos escolares, é preciso valorizar devidamente a história e cultura de seu povo, buscando reparar danos, que se repetem há cinco séculos, à sua identidade e a seus direitos. A relevância do estudo de temas decorrentes da história e cultura afro-brasileira e africana não se restringe à população negra, ao contrário, diz respeito a todos os brasileiros, uma vez que devem educar-se enquanto cidadãos atuantes no seio de uma sociedade multicultural e pluriétnica, capazes de construir uma nação democrática. [...] É importante destacar que não se trata de mudar um foco etnocêntrico marcadamente de raiz européia por um africano, mas de ampliar o foco dos currículos escolares para a diversidade cultural, racial, social e econômica brasileira. (BRASIL, 2004, p. 17)

No caso das modificações curriculares propostas pelas políticas afirmativas, a condução estatal das relações raciais deve reeducar as grandes parcelas da população que tomam parte nas práticas desenvolvidas nos estabelecimentos de ensino para a legítima necessidade de corrigir as desigualdades raciais. Afinal, nesta perspectiva reparatória e reeducativa, "cabe às escolas incluir no contexto dos estudos e atividades, que proporciona diariamente, também as contribuições histórico-culturais dos povos indígenas e dos descendentes de asiáticos, além das de raiz africana e europeia" (BRASIL, 2004a, p. 17). Empreendida através de modificações no currículo da Educação Básica, não deve apenas legitimar a inclusão socioeconômica dos grupos sociais racialmente discriminados, mas proporcionar as condições de possibilidade de uma redefinição, do ponto de vista estatal, do que definimos como identidade nacional brasileira, racialmente excludente ao longo de sua história.

Desse modo, as diretrizes curriculares também devem conduzir uma reescrita da própria história brasileira que leve em conta a contribuição, a partir de uma perspectiva positiva, dos diferentes grupos sociais racialmente discriminados, no processo de formação do País, permitindo que:

Entre os negros, poderão oferecer conhecimentos e segurança para orgulharem-se da sua origem africana; para os brancos, poderão permitir que identifiquem as influências, a contribuição, a participação e a importância da história e da cultura dos negros no seu jeito de ser, viver, de se relacionar com as outras pessoas, notadamente as negras. Também farão parte de um processo de reconhecimento, por parte do Estado, da 
sociedade e da escola, da dívida social que têm em relação ao segmento negro da população, possibilitando uma tomada de posição explícita contra o racismo e a discriminação racial e a construção de ações afirmativas nos diferentes níveis de ensino da educação brasileira. [...] Tais pedagogias precisam estar atentas para que todos, negros e não negros, além de ter acesso a conhecimentos básicos tidos como fundamentais para a vida integrada à sociedade, e ao exercício profissional competente, recebam formação que os capacite para forjar novas relações étnico-raciais. (BRASIL, 2004, p. 16)

A inclusão, nas diretrizes curriculares da Educação Básica, destes saberes, até então subjugados a permanecer fora do conjunto dos saberes veiculado pelas práticas pedagógicas desenvolvidas no âmbito escolar, também tem por objetivo desenvolver uma consciência, portanto uma postura política, anti-racista, que seja comum a negros e brancos. Ou seja, tais “pedagogias precisam estar atentas para que todos, negros e não negros, além de ter acesso a conhecimentos básicos tidos como fundamentais para a vida integrada à sociedade, e ao exercício profissional competente, recebam formação que os capacite para forjar novas relações étnico-raciais" (BRASIL, 2004, p. 16).

Fundamental para a efetividade da condução das relações raciais, a subjetivação da população em favor da reeducação das relações étnico-raciais deve ser realizada através das orientações contidas nas Diretrizes Curriculares Nacionais para a Educação das Relações Étnico-Raciais, nas quais o fenômeno da politização da questão racial se afirma como uma de suas principais frentes no campo da Educação. Através do currículo, a proposta de uma reeducação das relações étnico-raciais mantém uma íntima relação de imanência com o que chamei de dimensão política da raça e das relações raciais, formando um vínculo discursivo explícito.

\section{Referências}

BRASIL. Senado Federal. Estatuto da igualdade racial. Brasília: Senado Federal, 2011. 
BRASIL. Secretaria de Políticas de Promoção da Igualdade Racial. Plano Nacional de Promoção da lgualdade Racial. Brasília: SEPPIR, 2006.

BRASIL. Ministério da Educação e Cultura. Lei 10.639/200: diretrizes curriculares nacionais para a educação das relações étnico-raciais e para o ensino de história e cultura afrobrasileira e africana. Brasília: MEC/SEPPIR, 2004.

BRASIL. Ministério da Justiça. Plano nacional de direitos humanos II. Brasília: Presidência da República/Ministério da Justiça, 2002.

BRASIL. Ministério da Educação e Cultura. Lei de Diretrizes e Bases da Educação Nacional. Brasília: MEC, 1996 .

BRASIL. Ministério da Justiça. Plano Nacional de direitos humanos I. Brasília: Presidência da República/Ministério da Justiça, 1996b.

CARTA PÚBLICA AO CONGRESSO NACIONAL: todos têm direitos iguais na República Democrática. In FRY, Peter; MAGGIE et al.(Org.). Divisões perigosas: políticas raciais no Brasil contemporâneo. Rio de Janeiro: Civilização Brasileira, 2007, p. 345-347.

CARVALHO, José Murilo de. Cidadania no Brasil: o longo caminho. Rio de Janeiro: Civilização Brasileira, 2009.

CASTEL, Robert. A discriminação negativa. Petrópolis: Vozes, 2008.

FAUSTO, Bóris. História do Brasil. São Paulo: Didática, 2007.

FERNANDES, Florestan. O negro no mundo dos brancos. São Paulo: Global, 2007.

FREYRE, Gilberto. Casa Grande \& Senzala: formação da família brasileira sob o regime da economia patriarcal. São Paulo: Global, 2006.

FOUCAULT, Michel. A ordem do discurso. São Paulo: Edições Loyola, 2009.

FOUCAULT, Michel. Microfísica do poder. Rio de Janeiro: Edições Graal, 2006.

FOUCAULT, Michel. Vigiar e punir: nascimento da prisão. Petrópolis: Vozes, 2009.

GUIMARÃES, Antonio Sérgio. Acesso de negros às universidades públicas. Cadernos de Pesquisa, n.118, p. 247-268, 2003.

GUIMARÃES, Antonio Sérgio. Democracia racial: o ideal, o pacto e o mito. Novos Estudos. São Paulo, n. 61, p. 147-162, nov. 2001. 
GUIMARÃES, Antonio Sérgio. Raça e estudo das relações raciais no Brasil. Novos Estudos. São Paulo, n. 54, p. 147-156, jul. 1999.

HALL, Stuart. Da diáspora: identidades e mediações culturais. Belo Horizonte: Editora da UFMG, 2009.

HOBSBAWM, Eric J. Nações e Nacionalismo desde 1780. Rio de Janeiro: Paz e Terra, 1990.

HOFBAUER, Andreas. Uma história de branqueamento ou o negro em questão. São Paulo: Editora da Unespe, 2006.

KAMEL, Ali. Não somos racistas. Rio de Janeiro: Nova Fronteira, 2006.

KERN, Gustavo da Silva. Ações Afirmativas e educação: um estudo genealógico sobre as relações raciais no Brasil . 2012. Dissertação ( Mestrado em Educação) Programa de PósGraduação e Educação, Universidade Federal do Rio Grande do Sul. Porto Alegre, 2012. LOPES, Maura Corcini. Políticas de Inclusão e governamentalidade. Revista Educação \& Realidade. Porto Alegre, v. 34, n. 2, p. 153-169. maio/ago. 2009.

LOPES, Nei. Enciclopédia brasileira da diáspora africana. São Paulo: Selo Negro, 2004.

OLIVEN, Arabela Campos. Ações afirmativas na Universidade Federal do Rio Grande do Sul e seu significado simbólico. Revista de Educação. Santa Maria, v. 34, n. 1, p. 65-76, jan./abr. 2009.

MACHADO, Roberto. Foucault, a ciência e o saber. Rio de Janeiro: Jorge Zahar, 2009.

MACHADO, Roberto.. Por uma genealogia do poder (Introdução). In: FOUCAULT, Michel. Microfísica do poder. Rio de Janeiro: Edições Graal, 2006.

MAGGIE, Yvonne; FRY, Peter. A reserva de vagas para negros nas universidades brasileiras". Estudos avançados. v. 18, n. 50, p. 67-80. 2004.

MUNANGA, Kabengele. Rediscutindo a mestiçagem no Brasil: identidade nacional x identidade negra. Petrópolis: Vozes, 1999.

Movimento Negro Unificado. Carta de princípios do MNU. São Paulo: MNU, 1978.

NASCIMENTO, Abdias. O quilombismo. Petrópolis: Vozes, 1980.

ORGANIZAÇÃO DAS NAÇÕES UNIDAS. Declaração de Durban. África do Sul: ONU, 2001.

RIBEIRO, Darcy. O povo brasileiro: a formação e o sentido do Brasil. São Paulo: Companhia das Letras, 1995. 
SCHWARCZ, Lilia Moritz. Apresentação. In: FERNANDES, Florestan. O negro no mundo dos brancos. São Paulo: Global, 2007.

SCHWARCZ, Lilia Moritz. O espetáculo das raças: cientistas, instituições e questão racial no Brasil (1870-1930). São Paulo: Companhia das Letras, 1993.

STEPAN, Nancy Leys. A hora da eugenia: raça, gênero e nação na América Latina. Rio de Janeiro: Editora Fiocruz, 2005.

VEIGA-NETO, Alfredo. Equidade, igualdade e diferença: implicações para o currículo. Porto: Universidade do Porto, 2010.

VEIGA-NETO, Alfredo. Foucault \& a educação. Belo Horizonte: Autêntica, 2003.

VEIGA-NETO, Alfredo; LOPES, Maura Corcini. Inclusão e governamentalidade. In: Educação \& Sociedade, Campinas, v. 28, n. 100, p. 947-963, set./dez. 2007. 